\title{
Design and Research on Collaborative Learning Program Based on Cloud-services
}

\author{
Linna Huang, Fenghua Liu, Chunli Liu \\ Department of Computer Engineering \\ Cangzhou Normal University \\ Cangzhou, China \\ Hln0322@163.com
}

\begin{abstract}
Cloud computing has changed people's work, life and learning while more and more collaborative learning based on cloud services are applied to the field of education and teaching. This paper analyzes the collaborative learning characteristics supported by cloud computing and designs collaborative learning programs of College Computer Basis based on cloud services.
\end{abstract}

Keywords- cloud services; collaborative learning; learning programs

\section{INTRODUCTION}

With the help of network, people are able to get a lot of information and communicate with each other quickly and easily while learning is no longer confined to the classroom. So the network has become an important way for more and more people to obtain knowledge and information. In recent years, with the rapid development of the Internet, an emerging computing model - "cloud computing" has caught more and more attention [1]. Cloud computing refers to a network of hundreds of thousands or even millions of cheap servers providing users with computer services in a remote location [2]. Cloud computing, with high reliability, scalability, large-scale virtualization, generality and other characteristics, not only changes people's work and lifestyle ,but also affects teaching ideas, models and methods.

Cloud services by Google have the following characteristics: data in the cloud with no worry about being lost and with no backup, software in the cloud with no need to download dynamic upgrade, ubiquitous cloud computing ready to be logged in and used with any devices, infinitely powerful cloud computing with unlimited space and unlimited users. In fact, cloud services provided by cloud computing have been already around us and are widely enjoyed, such as web search, e-mail, QQ group and Web Albums. The reason why it is called "cloud service" is that they rely on a large network server group to provide services, but we do not know where these servers are.

In the field of education and teaching, cloud computing is the basic environment and platform for future network learning, affecting deeply the learners' personal learning environment, the construction of school resources and development of educational information system. Therefore cloud services by cloud computing are used widely.
Professor Li Jiahou put forwards a concept of Cloud Computing Assisted Instruction (CCAI) [3], promoting the use of cloud computing services to serve auxiliary teaching, and the core by cloud computing is collaborative learning. Cloud computing, with its application convenience and service supportability, provides a broader platform than ever before for collaborative learning. Many teachers at present are organizing collaborative learning activities as learninghelpers to supplement classroom teaching to improve teaching effectiveness.

\section{THE DEFINITION OF ClOUD-BASED COLLABORATIVE LEARNING}

\section{A. Collaborative Learning}

Professor Huang Ronghuai from Beijing Normal University [4] considers that collaborative learning refers to all related cooperation activities, which maximizes personal and others' achievements under certain incentive mechanism for common learning goals, and where students participate the activities by group forms Collaborative learning is characterized by:

- Collaborative learning is carried out in small groups.

- Collaborative learning stresses the importance of the learning process.

- Collaborative learning stresses the common progress of the team members, and the learning outcomes are completed by all team members.

- Evaluation of collaborative learning includes both learning outcomes and learning process.

\section{B. Collaborative Learning Based on Cloud Services}

The cloud-based collaborative learning is an extension of Computer Supported Collaborative Learning [5]. Computer Supported Collaborative Learning is named CSCL in short, referring to a kind of collaborative learning assisted and supported by computers, by using computer technology (especially the multimedia and network technology) [6].

Cloud-based collaborative learning (Cloud Computing Supported Collaborative Learning), means here CCSCL [7]. The concept of Cloud Computing Supported Collaborative Learning, by Zhou Li from Shanghai Normal University, is defined as follows: it is a technical method assisted by cloud computing with collaborative learning supported by cloud computing, where a "cloud" environment can be established 
in the clouds to make exchanges between students and teachers as an extension and development of the computersupported collaborative learning. In this sense, CCSCL is a subset of CSCL. But from another perspective, you can regard CCSCL as a development of CSCL and another new stage in the history of the development of collaborative learning.

\section{CHARACTERISTICS OF THE CLOUD-BASED COLLABORATIVE LEARNING}

Compared with on-line collaborative learning, cloudbased collaborative learning has the following characteristics [8]:

(1) The technology is no longer the burden of teachers and learners. All the technical issues, including the installation of the software tools, later updates and maintenance, technical help, etc, all solved by the cloud service providers.

(2) Cloud services are available to richer learning resources for learners and teachers while learners and teachers can search for learning resources more quickly and easily. Google, for example, has powerful search function, including a blog search, college search, life search, image search, code search, web search, personalized search, book search, academic search, SMS search, etc.

(3) Cloud services can provide more effective collaborating ways for learning. Cloud services are free from the constraints of the hardware environment. As long as the Internet is available, collaborative learning can be done anywhere, and anytime.

(4) The relationship between teachers and students tends to be more equal. Students' active construction of learning makes themselves both the designers of collaborative learning activities and performers. Teachers can be involved in collaborative activities as students while as guiding roles.

(5) Cloud services can save real-time record of the online activities of teachers and learners to provide a basis for the evaluation of learning, and also to provide rich learning evaluation methods, which makes learning evaluation more fair and equitable.

(6) Cloud services are in favor of the student's personality development and team awareness training. Students in collaborative activities can develop their own emotion, personality, thinking ability, while they experience the culture of teamwork in a collaborative process, forming a sense of team.

\section{APPLICATION OF ClOUd SERVICES FOR COLLABORATIVE LEARNING}

\section{A. Google Education Suite}

Google Education Suite integrates cloud service functions provided by Google, by packing Gmail, Google Calendar, Google Talk, Google documents and Google Sites as a whole, to help teachers build personalized teaching environment, which is easy to operate, easy to manage with powerful function.

security and free of charge. Google Education Suite provides collaborative learning through the following functions: collaborative arrangements of teaching schedule, collaborative arrangements of learning projects, collaborative management of teaching activities, collaborative management of teacher-student staff, online collaborative word processing, online collaborative spreadsheet processing, database collaboration, online collaboration presentation of design and display, online cloud storage of data; online (offline) use of Google's other cloud services (search, pictures, e-mail, instant information, blog, forum, community, Earth...) and so on.

With Google cloud services, students can save the needed documents of teaching activities in Google Docs, can upload teaching picture materials and works to Google Picasa Web Albums, without worry about loss or damage of data. Meanwhile, strict rights management strategy can help to safely share data between the teachers and students. This way, you can enjoy the best, and the most secure service, which is even more convenient than saving money in the bank, without spending money. With Google Education Suite, we can expand teaching space and time, support students in active learning and collaborative learning. Teachers in the Google cloud service environment can create teaching environments, can design teaching resources, can organize collaborative teaching activities, can carry out the teaching evaluation and management of teaching-learning process.

Google Sites [9] Google is a teacher-student collaboration platform built for teachers and learners by Google cloud service, reflects the people-oriented purpose, meet the needs of learners' personalization. This collaboration platform can take advantage of the space and site-construction methods provided by Google, make teachers build their own teaching website with zero economic cost, and build their own teaching websites and subject websites with low-technology costs. And other services provided by Google module can be used fully, such as presentations, spreadsheets, online documents, photo albums, etc. Only by using the browser, the teachers can complete the record, storage, organization and accumulation of their own teaching content, can complete the electronic preparation work, can complete collaborative lesson planning and other work, can complete a simple survey testing and feedback, can complete teacher-student interaction, and so on. If it is used in the research study, teachers and students can collaborate to carry out the study of a subject, complement research materials, exhibit collection of resources, publish research results. You can also show it as a platform of learning resource, a platform of knowledge complementary, a platform of marking school assignment, a space of extending learning.

Under this method, the construction of the site platform, data collection, storage, management and maintenance of the site can fully take advantage of cloud resources,which students can share and create collaboratively with help of teachers. As guide scholars, teachers need to do more collaborative mechanisms and collaborative evaluation design. The Website page views statistics provided by Google Analytics can help teachers have intuitive and convenient access to the collaborative learners' visits and 
interest in website programs, which can be thought either as a collaborative evaluation of reference, or as an effective support for collaboration improvement. Google Sites significantly saves the time to build a learning site, without too much technical support. Teachers can select the template to build websites according to their own curriculum frameworks and coordination mechanism, whose features of simply easy use and rich technical content can support a good choice for collaborative learning.

\section{B. QQ Group Service}

Google's cloud computing models and Google Education Suite provide theoretical and practical support for the application of Cloud Service Assisted Instruction. From the application principle, the QQ group service is also available as a Cloud Service Assisted Applied Case. Tencent is a pioneer in cloud service, which has a very wide range of application base. So Tencent's QQ group can be built more easily than that of Google site. Its QQ group services have been expanding to provide more services.

By using QQ group in collaborative learning, we can use some of the typical functions of QQ group to support our activities. For instance, Group sharing can be convenient for collaborators to share and expand learning resources. Group information can release information and dynamic announcement of learning. Developing group community can build a culture of collaboration theme. Publishing articles and uploading images and other tools can help collaborators show and exchange their learning outcomes. Multiplayer session may organize online discussions and exchange learning experiences during the communication. Under thus collaborative learning, teachers can design collaboration theme, organize collaborative process, guide the collaborative goals and complete collaborative evaluation. QQ group, as an applied case assisted by cloud computing, is very popular with its broad user base, rich service projects and convenient operation processes. In teaching practice, the author has applied it in extracurricular collaborative learning, in students' work evaluation and in all aspects of student management, achieving good results.

\section{ClOUd-BASED COLLABORATIVE LEARNING}

\section{Program Design for College Computer Basic Course}

Cloud computing model will develop a new field of education, and also create a whole new environment for information sharing, information collaboration and learning. With the gradual development and popularization of the cloud computing model, information of schools, educational institutions and individuals will gradually migrate to the "cloud", which will have a positive impact on network learning. On one hand, learners can, with the help from cloud computing service, be freed to choose the learning contents and learning styles through better use of information resources and services. On the other hand, the education management institutions and educational researchers can make better management of teaching resources, conduct instructional design and optimize the teaching process. For educational and technical workers, both grasping the idea of the cloud computing technology and its application mode, and applying it in the design and development of network learning system, will bring new impetus for network learning.

\section{A. Collaborative Learning Platform Design for College Computer Basic Course}

College Computer Basis is an important foundation course in higher schools as a required course to improve contemporary college students' information literacy. Information literacy contains mainly information acquisition, information utilization and information screening, which is an important component of the overall quality of human in information society. Cloud-based collaborative learning of College Computer Basis is to improve students' abilities of learning to collect, organizing, and using information [10].

According to features and design of College Computer Basis course, in the collaborative learning platform, we initially divide the course structure into four modules: course overview, course content, course resource, learning from teaching. Course-overview module includes three submodules: course description, course feature, course guiding, which provides learners with clear course navigation. Course-content module includes three sub-modules: course syllabus, course teaching-plan, on-line assignment, which provides the learners' free self-education with content support. Course-resource module includes three sub-modules: expansion of resource, case study, tool downloading, which provides the learners with rich resources and tools. Learning from teaching module includes 3 sub-modules: online Q \& A, forum, show case, which improves thinking ability in the interaction between teachers and students, also promotes the development of collective wisdom during collaboration activity. Learners, at any time and anywhere, can have access to the course websites through a browser to make selfdirected learning and collaborative learning. The course platform framework design is shown in Figure 1.

\section{B. Design ideas of collaborative learning platform}

(1) To put forwards clear expectations: It can, through the "Course Overview" module of the course platform, provide learners with clear navigation, which makes the learners understand the course nature, features, learning methods and main content. It also can, through the Online Assignment, give challenging problems or projects to stimulate learners' intrinsic motivation and train their abilities of analyzing and solving problems.

(2)To enhance the interaction between teachers and students: Through the course platform "Online Q \& A", "Forum", as well as E-mail, QQ and other information technology tools, teachers and students can communicate with each other and exchange between them, which makes teachers keep control of learners' learning situation, emotional tendencies to do timely individual guidance and support. The learners should answer all questions, participate in the course topic exchanges and discussion to improve selfregulation ability and self-examination ability.

(3) To promote collaboration and mutual assistance: Teachers present the theme projects or personal learning interest while the learners form a project team freely to create a learning community or virtual learning community 
through the course platform. They should be active in the group collaborative learning to improve the sense of teamwork and realize open learning.

(4) To enhance active learning: It can, through teaching plans, expansion of resource, case study, technology tools, online assignment, show case by the course platform , as well as communication with others or discussion, promote learners consciously to be engaged in learning, and to advocate learners to create course learning materials actively, to participate in the development of curriculum platform, to make knowledge construction in the process of solving the problems or projects in order to enhance their capacity and awareness of active learning.

(5) To focus on timely feedback: It can, through Online Q \& A, Forum, Show Case provided by the course platform, make timely record, track of student's learning process, report their learning outcomes, and ask learners to write a blog, to sum up timely, to reflect on personal learning process, and to make ongoing self-evaluation and management.

\section{CONCLUSION}

Cloud computing education will promote change of the concept of education, change of education development mode, change of information technology and change of organizational structure and educational institutions. The 21stcentury teaching philosophy is based on the students while learning modes change from individual learning into collaborative learning. Cloud services can integrate network resources. So it can provide personalized services according to the needs of teachers and students. With the increasing number of users, the integration of resources and the supply of services will be more humanized and easy to obtain. In the background of quick "cloud services", teachers can, based on the actual situation of the local teaching, by taking full advantage of cloud computing software, storage, security elements, build personalized teaching environment to support effective teaching, collaborative learning, and develop students' high-level thinking skills and promote training of collective wisdom for high quality of education.

\section{REFERENCES}

[1] Li Jiahou, "Low-carbon Education and Cloud Computing Assisted Instruction,” China IT Education, pp. 73-77, January 2010.

[2] Zhao Yuhong and Liu Quanxi, "Applications of Cloud Computing Assisted Instruction (CCAI) in Collaborative Learning," Fujian Computer, vol. 26, pp. 85-124, June 2010.

[3] Ma Qiang, Fu Yanru, "Research on design of collaborative learning supported by cloud computing aided instruction-CCAI," Journal of Ningbo Polytechnic, vol. 15, pp. 59-62, May 2011.

[4] Huang Ronghuai, Computer Supported Collaborative Learning-Theory and Method, Beijing: People's Education Press, 2003.

[5] Zhao Jianhua, Li Jiahou, Computer-supported Collaborative Learning, Shanghai: Shanghai Education Press, 2006.

[6] Zhang Jie, Pei Fang, "Collaborative Learning Study of Cloud Computing Aided Teaching on World University City," Computer CD Software and Applications, pp. 229-231, March 2012.

[7] Li Jian, "On Computer-supported Collaborative Learning Under the Support of Cloud Computing, Journal of Jixi University,” vol. 11, pp.5-6, Oct. 2011.

[8] He Shuangquan, “On Design Strategy of the Collaborative Learning Activities under Cloud Computing Assisted Instruction," Educational Technology and Equipment in China, pp.142-144, No.36, 2010.

[9] Yang Bin, Ren Xinying, “Construction of 'Cloud Services' Ring System in Higher Education,” Software Guide · Educational Technology, pp.93-95, August 2011.

[10] Kang Junxia, "Case Studies and Analysis of Collaborative Learning in the Teaching of Basic Computer,” Market Modernization, pp. 9698, No.22, 2011.

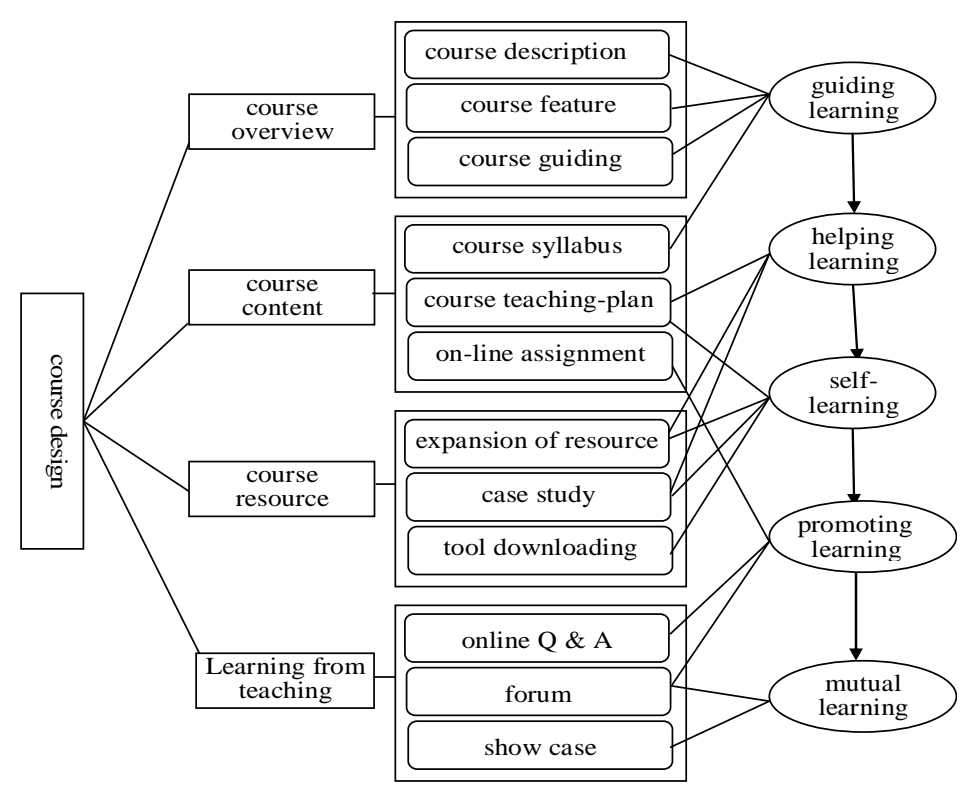

Figure 1. Design of course collaborative learning platform framework. 